\title{
Special Issue on ICARSC 2018
}

\section{Hugo Costelha ${ }^{1} \cdot$ João Calado $^{2} \cdot$ Luís Conde Bento $^{1} \cdot$ Paulo Oliveira $^{2}$}

Published online: 2 January 2020

(C) Springer Nature B.V. 2019

Dear colleagues and readers:

We are pleased to present you this special issue, bringing you the most relevant papers describing work whose roots were initially published in ICARSC2018, an international conference held every year in Portugal, together with a Robotics competition, promoting and discussing Autonomous Robot Systems and Competitions. The conference had 42 accepted papers from 21 countries in six continents, reviewed by 85 committee members, from 22 countries. The work described in the papers throughout this issue represent significant new developments not yet presented at the conference, ranging from localization and planning to systems development, both with ground and aerial autonomous robots. Each of the papers in this issue was thoroughly analysed by at least two reviewers, with several iterations when necessary. We thank the authors and the reviewers for their work and patience throughout this process.

This issue, which had the support of the Portuguese Robotics Society (http://www.sprobotica.pt/), resulted from a joint work between us, the guest editors, and the Springer JINT editorial board, to bring you up to date, relevant developments in the robotics field. We hope you enjoy this issue.

Hugo Costelha

hugo.costelha@ipleiria.pt

João Calado

jcalado@dem.isel.ipl.pt

Luís Conde Bento

luis.conde@ipleiria.pt

Paulo Oliveira

paulo.j.oliveira@tecnico.ulisboa.pt

1 Polytechnic of Leiria, Leiria, Portugal

2 Polytechnic of Lisbon, Lisbon, Portugal 